\title{
PRORAČUN DOGRADNJE OBJEKTA VI SPRATA VISOKE S̆KOLE ELEKTROTEHNIKE I RAČUNARSTVA U ULICI VOJVODE STEPE BR. 282 U BEOGRADU
}

\author{
Miroslav T. Bešević ${ }^{1}$ \\ Dragan Stojiljković ${ }^{2}$ \\ Prokić Aleksandar ${ }^{3}$ \\ Tabaković Dragana 4
}

УДК: 69.059.35:727.4

DOI:10.14415/konferencijaGFS 2015.012

Rezime: Za potrebe dogradnje VI sprata Visoke škole elektrotehnike i računarstva $u$ Beogradu bilo je potrebno izraditi projekat nadogradnje postojećeg objekta. Postojeći objekat se nalazi u ulici Vojvode Stepe i spratnosti je Pr+5 spratova, dimenzija u osnovi (deo koji se dograđuje) $36.8 \times 15.03 \mathrm{~m}$, a predviđa se nadogradnja objekta cca $550 \mathrm{~m} 2 \mathrm{u}$ obliku mansardnog krova. Novoprojektovana noseća konstrukcija dogradnje je u vidu čelične konstrukcije sa pokrivačem od sendvič samonosećih Fe plastificiranih panela (veći deo krovne površi) i u kombinaciji sa drvenim rogovima na strmijim ravnima krova, gde je predviđen krovni pokrivač u obliku eternit ploča. Glavni noseći sistem čelične konstrukcije je u statičkom smislu dvozglobni ram oslonjen na postojeće gredestubove u fasadnim ravnima. Za izradu noseće čelične konstrukcije koriste se limovi, gotovi profili i zavareni profili (grebenjača) od čelika kvaliteta S235, a nastavci se ostvaruju običnim zavrtnjima klase čvrstoće 5.6 i ugaonim šavovima. Postojeći objekat je izveden kao zidana konstrukcija sa vertikalnim armiranobetonskim stubovima $i$ vertikalnim serklažima, dok je međuspratna konstrukcija izvedena kao sitnorebrasta konstrukcija oslonjena na sistem greda i serklaža. Fundiranje objekta je izvedeno na armirano betonskim trakama-roštilju, različitih poprečnih preseka u skladu sa statičkim uticajima.

Ključne reči: nadogradnja, ispitivanje, snimanje, čelična konstrukcija, montažni nastavci, rekonstrukcija,sanacija.

\footnotetext{
${ }^{1}$ Prof..dr Miroslav T. Bešević, dipl inž građ., Građevinski fakultet Subotica, Kozaračka 2a, Univerzitet u Novom Sadu tel: 024- 554-300, e -mail: miroslav.besevic@gmail.com

${ }^{2}$ Dragan Stojiljković ,dipl inž. arh., Beograd, e -mail: dsvs.stoj@gmail.com

${ }^{3}$ Prokić Aleksandar,dipl inžgrađ., Građevinski fakultet Subotica, e -mail:aprokic@eunet.rs

${ }^{4}$ Tabaković Dragana,dipl.inž.građ., Građevinski fakultet Subotica, e -mail:draganatabakovic@gmail.com
} 
International conference

Contemporary achievements in civil engineering 24. April 2015. Subotica, SERBIA

\section{UVOD}

Za dogradnje VI sprata Visoke škole elektrotehnike i računarstva strukovnih studija u Beogradu bilo je potrebno izraditi projekat dogradnje postojećeg objekta. Postojeći objekat je izgrađen paralelno sa ulicom Vojvode Stepe i spratnosti je $\mathrm{Po}+\mathrm{Pr}+5$ spratova dimenzija $(\mathrm{a} \times \mathrm{b}=36.8 \times 15.10 \mathrm{~m})$. Novoprojektovana noseća konstrukcija se predviđa $\mathrm{u}$ vidu čeličnih poprečnih dvozglobnih ramova, postavljenim na razmacima od $1=3.60 \mathrm{~m}$. Preko poprečnih glavnih nosača postavljaju se rožnjače od valjanih profila na koje se postavlja pokrivač u vidu čeličnog sendvič samonosećeg Fe plastificiranog panela (veći deo krovne površi) i u kombinaciji sa drvenim rogovima na strmijim ravnima krova, gde je predviđen krovni pokrivač u obliku eternit ploča. Glavni noseći poprečni ram oslanja se na postojeće armiranobetonske grede preko ležišne ploče i vezom ostvarenom ankerima zalivenim epoksidnim malterom. Na Sl. 1 su prikazani osnova i presek dogradnje i uticaji od vetra.

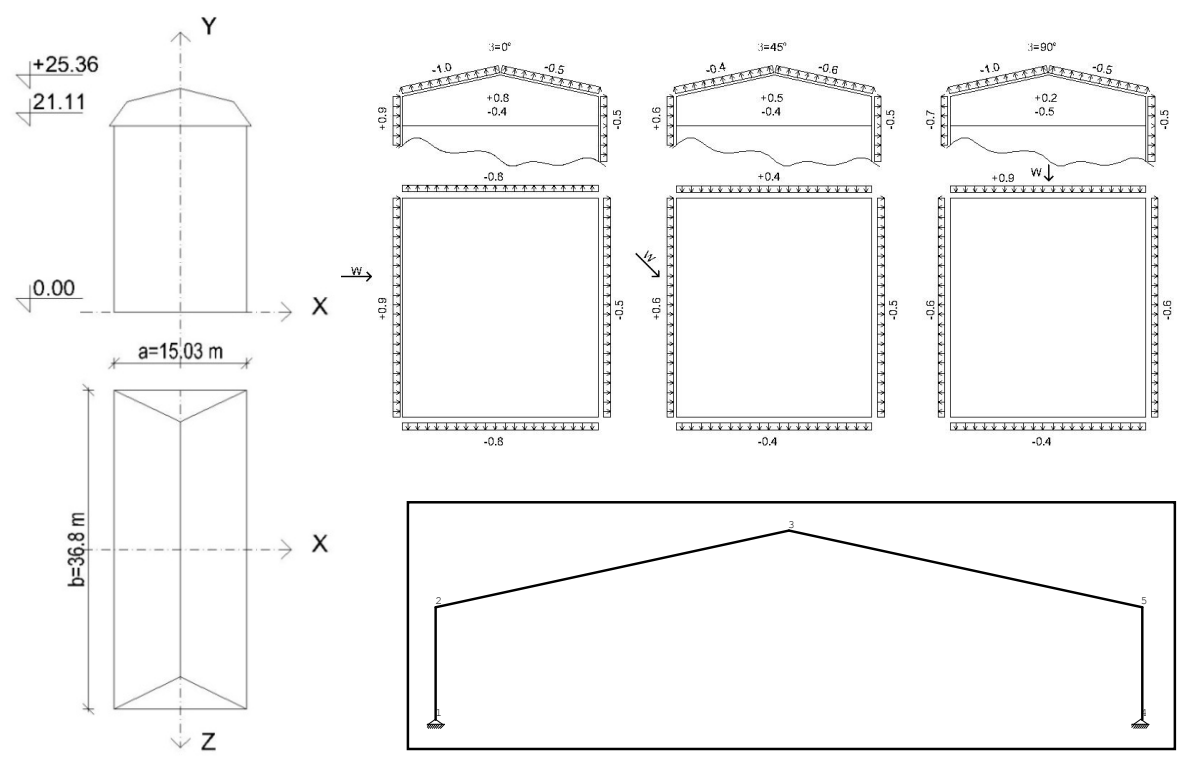

Slika 1. Osnova, presek $i$ dejstva na konstrukciju

Postojeći objekat je izveden kao zidana konstrukcija sa vertikalnim armiranobetonskim stubovima, serklažima i sitnorebrastom tavanskom konstrukcijom, koja se oslanja na poprečne i podužne grede različitih poprečnih preseka. Konstrukcija stepeništa je izvedena kao puna armiranobetonska ploča oslonjena na poprečne podvlake. Fundiranje objekta je izvedeno na armiranobetonskim trakama-roštilju, različitih poprečnih preseka, u svemu prema arhivskom projektu, a prema statičkim uticajima za svaki temelj.

Kod dogradnji postojećih objekata sprovodi se sveobuhvatna analiza parametara koje je potrebno utvrditi i obuhvata sledeće:

\section{4}


Међународна конференција

Савремена достигнућа у грађевинарству 24. април 2015. Суботица, СРБИЈА

- Utvrđivanje postojećeg konstruktivnog sistema postojećeg objekta (vizuelni pregled sa snimanjem svih neophodnih mera i dimenzija),

- Analiza postojeće tehničke dokumentacije,

- Ispitivanje kvaliteta ugrađenih materijala u konstrukciju,

- Izrada geomehaničkog elaborata i utvrđivanje dimenzija temeljne kostrukcije,

- Analiza geodetskih osmatranja repera na objektu.

\section{NOVOPROJEKTOVANA KONSTRUKCIJA}

Glavna noseća konstrukcija nadogradnje ravnog krova postojećeg objekta je projektovana od čelika (primena montaže i suvih postupaka), a sekundarna, u strmijoj krovnoj ravni $\left(\alpha=74,6 C^{0}\right)$ u vidu drvenih rogova raspona cca $2.20 \mathrm{~m}$, kao i daščane oplate. Poprečni dvozglobni noseći ramovi su od IPE 300 i nalaze se između osa 2-10. Veza između novoprojektovane čelične konstrukcije i postojeće konstrukcije ravnog krova iznad petog sprata se ostvaruje postavljanjem para ankera koji se postavljaju u obodnu armiranobetonsku gredu. Ankeri su dimenzionisani tako da mogu da prime i sile zatezanja, dok se sile pritiska od reakcija poprečnog rama preko ležišne čelične ploče direktno prenose na postojeću armiranobetonsku konstrukciju. Na Sl. 2 se prikazuje

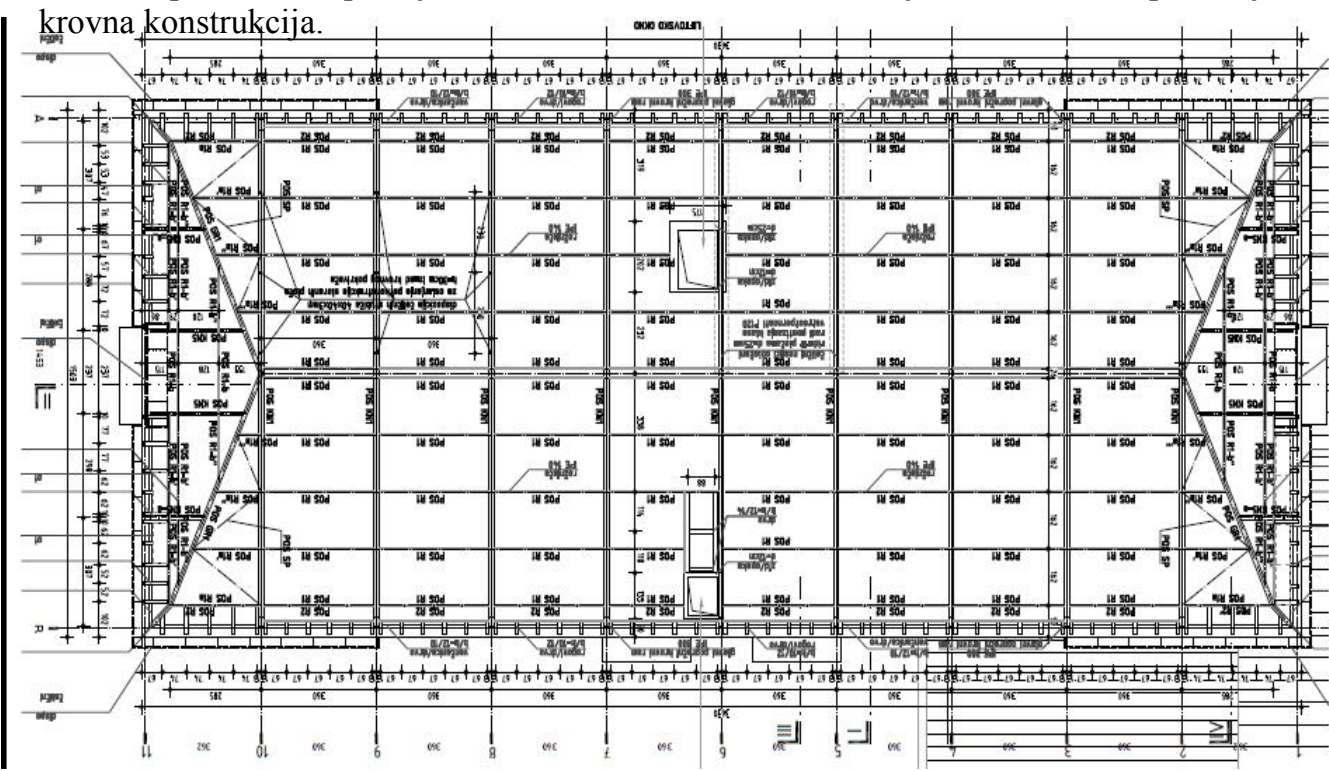

Slika 2 Osnova krovne konstrukcije sa POS-K+

Krutost krovne ravni je obezbeđena poprečnim krovnim spregovima uz kalkanske glavne i sekundarne čelične nosače u kalkanu. Vertikalni spregovi primaju i prenose uticaje na postojeću konstrukciju. Podužna krutost dogradnje je dodatno osigurana krutošću donjeg dela krova ostvarenom daščanjem preko drvenih rogova. U toku montaže može se 


\section{$41^{\text {th }}$ ANNIVERSARY FACULTY OF CIVIL ENGINEERING SUBOTICA}

International conference

Contemporary achievements in civil engineering 24. April 2015. Subotica, SERBIA

postaviti u polovini dužine montažni podužni portal dodavanjem podvlake u gornjoj ivici krova. Krovni puni limeni nosači su pod nagibom od 12 stepeni. Krovni poprečni dvozglobni nosači su pri oslanjanju na ležišnu ploču dimenzije $200 \mathrm{~mm}$, a veza donjeg dela rama-stuba je zavarena na ležišnu ploču debljine $10 \mathrm{~mm}$. Krov je na četiri vode, dobija se upotrebom grebenih nosača I 240 poprečnog preseka, gde je gornja nožica prilagođena podužnoj odnosno poprečnoj krovnoj ravni. Sve rožnjače su statičkog sistema proste grede i projektovane su kao IPE140. Veze sa glavnim nosačima se ostvaruju preko vertikalnih limova koji su zavareni za rebro glavnog poprečnog rama IPE 300 i rebra rožnjače sa dva zavrtnja M16 klase čvrstoće 5.6. Vertikalna ukrućenja su zavarena za rebro poprečnog rama sa dva ugaona šava debljine $a=3 \mathrm{~mm}$. Na Sl. 3 je dat poprečni presek dogradnje.

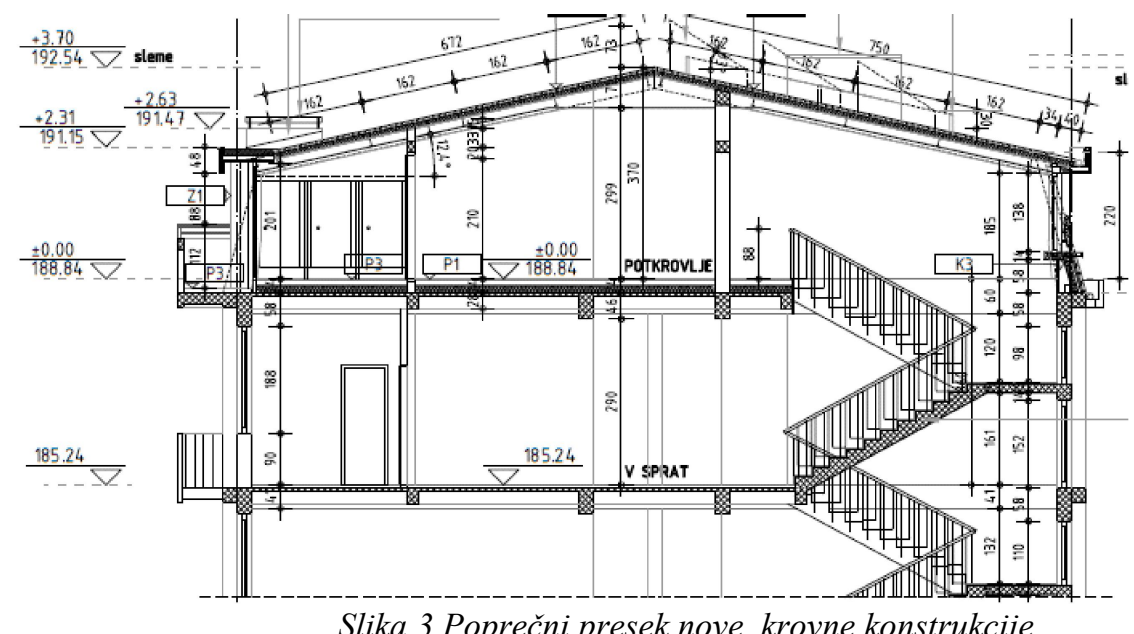

U ravni rožnjača predviđena su dva poprečna krovna sprega od ukrštenih dijagonala, koji svoje reakcije predaju vertikalnim spregovima u podužnim ravnima krova. Krovni spregovi su projektovani od $2 \mathrm{~L} 60 \times 60 \times 5 \mathrm{~mm}$ profila . U podužnim zidovima se rogovi oslanjaju na venčanicu u nivou poda i na prvu rožnjaču, dok se u poprečnoj krovnoj ravni rogovi osim navedenog oslanjaju i na poprečne rožnjače. Rogovi su dimenzija $\mathrm{b} / \mathrm{d}=10 / 12 \mathrm{~cm}$ i predviđeni su od četinara II klase, dok se na njih direktno postavlja daščana oplata, a veza se ostvaruje ekserima. Krov je pokriven u vidu sendvič Fe-panela (deo krova sa manjim nagibom) i eternit ploča za deo krova sa većim nagibom.

Proračun veze nosača IPE 300 sa postojećom armiranobetonskom gredom u nivou VI sprata: 
Међународна конференција

Савремена достигнућа у грађевинарству 24. април 2015. Суботица, СРБИЈА

$$
\begin{aligned}
& \max N=49.32 \mathrm{kn} / \mathrm{cm}^{2} \\
& \max Q=33.17 \mathrm{kn} / \mathrm{cm}^{2} \\
& \sigma_{b}=\frac{49.23}{20 x 24}=0.10 \mathrm{kn} / \mathrm{cm}^{2}, \\
& l_{x} / l_{y}=12 / 17=0.71 \Rightarrow \kappa=4.94 \\
& \mathrm{~m}_{y}=\frac{1}{4.94} x 0.10 x 12^{2}=2.92 \mathrm{kncm}, \\
& W_{p l}=4.5 \times 1.4 / 6=1.05 \mathrm{kn} / \mathrm{cm}^{2}
\end{aligned}
$$

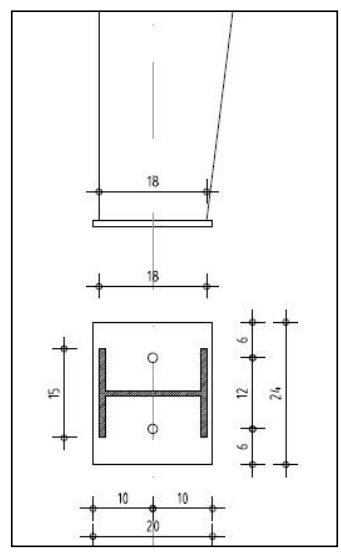

Za ankere se usvajaju 2 M16, koji se moraju zaliti epoksidnim malterom uz minimalnu dubinu ankerovanja od $20 \mathrm{~cm}$.

Svi konstruktivni elementi od drveta se izvode od četinara II klase. U fazi montaže potrebno je privremenim spregovima obezbediti stabilnost montirane konstrukcije u oba pravca sve do uspostavljanja konačne veze sa podužnim i poprečnim zidovima, odnosno njihovim gredama i serklažima i postavljanje svih poprečnih i podužnih spregova, kao i postavljanje daščane oplate u ravni krova. Priprema površina čelične konstrukcije mora odgovarati odredbama Pravilnika o zaštiti čeličnih konstrukcija od korozije. PPZ zaštita čelične konstrukcije obuhvata nanošenja protivpožarnih premaza u vidu premaza FIRESTOP, koji se sastoji iz osnovnog antikorozionog prajmera, zatim se nanosi intumescentni premaz i na kraju završni premaz (sistem ekspandirajućih protivpožarnih premaza, Jugohem AD ili slično). Pre početka izvođenja konstrukcije potrebno je sve mere na objektu prekontrolisati merenjem na licu mesta i uporediti sa datim u projektu kako bi se eventualne izmene dužina, raspona, sistema, rastojanja itd. blagovremeno unele u radioničku (izvođačku) dokumentaciju.

\section{POSTOJEĆA KONSTRUKCIJA OBJEKTA}

Snimanjem geometrije nosećih konstruktivnih elemenata (nosećih zidanih zidova, vertikalnih stubova i serklaža, kao i elemenata međuspratne konstrukcije, odnosno analizom overene arhivske tehničke dokumentacije, konstatuje se da su zidovi debljine $12,20,25,38$ i $51 \mathrm{~cm}$, a međuspratna konstrukcija je polumontažna sitnorebrasta konstrukcija. Fundiranje je izvedeno na armiranobetonskim trakama različite debljine i međusobno povezane u roštilj. Vizualnim pregledom objekta nisu ustanovljene značajne promene na konstrukciji zidova i stubova, dok se za međuspratnu konstrukciju nije moglo utvrditi zbog spuštenog plafona. Analizom opterećenja na postojeću konstrukciju iznad petog sprata, kao i upoređivanjem sa novoprojektovanim opterećenjima može se zaključiti da su približne vrednosti manje od postojećih, $q_{p k}=5.30 \mathrm{kn} / \mathrm{m}^{2} \cong q_{n p r}=4.7 \mathrm{kn} / \mathrm{m}^{2}$, a to znači da postojeća konstrukcija (međuspratna) može sa primi novoprojektovano opterećenje od dogradnje. Pregradni zidani zidovi se zidaju iznad postojećih zidova oko 


\section{$41^{\text {th }}$ ANNIVERSARY FACULTY OF CIVIL ENGINEERING SUBOTICA}

International conference

Contemporary achievements in civil engineering 24. April 2015. Subotica, SERBIA

stepeništa i za sanitarne čvorove. Svi ostali novi zidovi se izvode u suvom stanju u vidu gips karton ploča na čeličnoj potkonstrukciji. Za potrebe vertikalne komunikacije vrši se delimično rušenje postojeće krovne konstrukcije pos 600+ iznad stepenišnih krakova i izvodi se novo armiranobetonsko stepenište. Postojeća konstrukcija objekta se mora proveriti za uticaje od dogradnje. Sprovedena je sveobuhvatna analiza uticaja od postojećeg i novododatog opterećenja. Proračun je sproveden korišćenjem programskog paketa Tower. Kontrolnim proračunom je dokazana stabilnost postojeće konstrukcije i izvršeno je poređenje sa uticajima iz arhivskog projekta. Na Sl. 4 se daje overeni izvod iz arhivskog projekta, kao i prostorni model korišćen za kontrolni statički proračun, a na Sl. 5 se prikazuje kontrolni statički proračun temelja objekta sa dogradnjom. U analizi napona i sleganja temelja korišćen je i geomehanički elaborat.
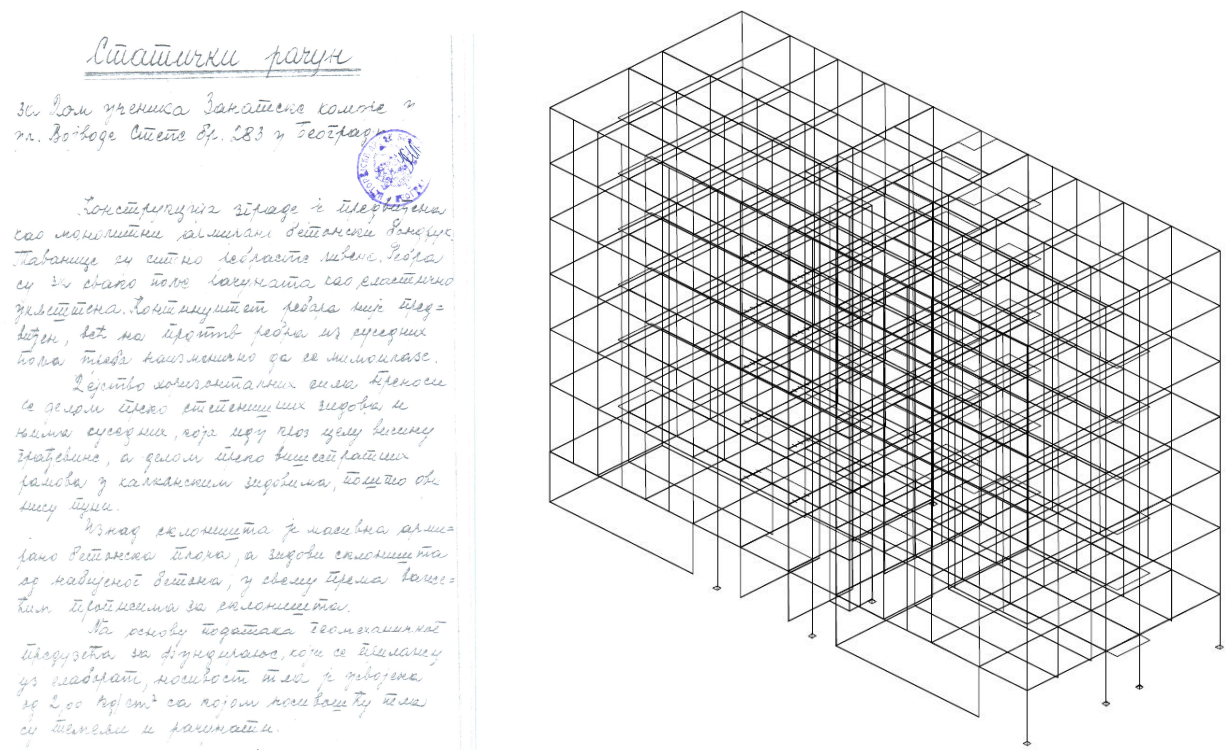

Slika 4 Arhivski statički proračun i kontrolni proracun-model

Analizom vertikalnog opterećenja na temeljnu spojnicu od postojećeg i novoprojektovanog opterećenja može se zaključiti da je to povećanje maksimalno $5 \%$ samo na temeljnoj traci T1 i T5, dok je za temeljne trake T2 i T3 manje $(-2,2 \%)$, što je manje od $10 \%$ prekoračenje dopuštenih napona na temeljnu spojnicu. 
Међународна конференција

Савремена достигнућа у грађевинарству 24. април 2015. Суботица, СРБИЈА
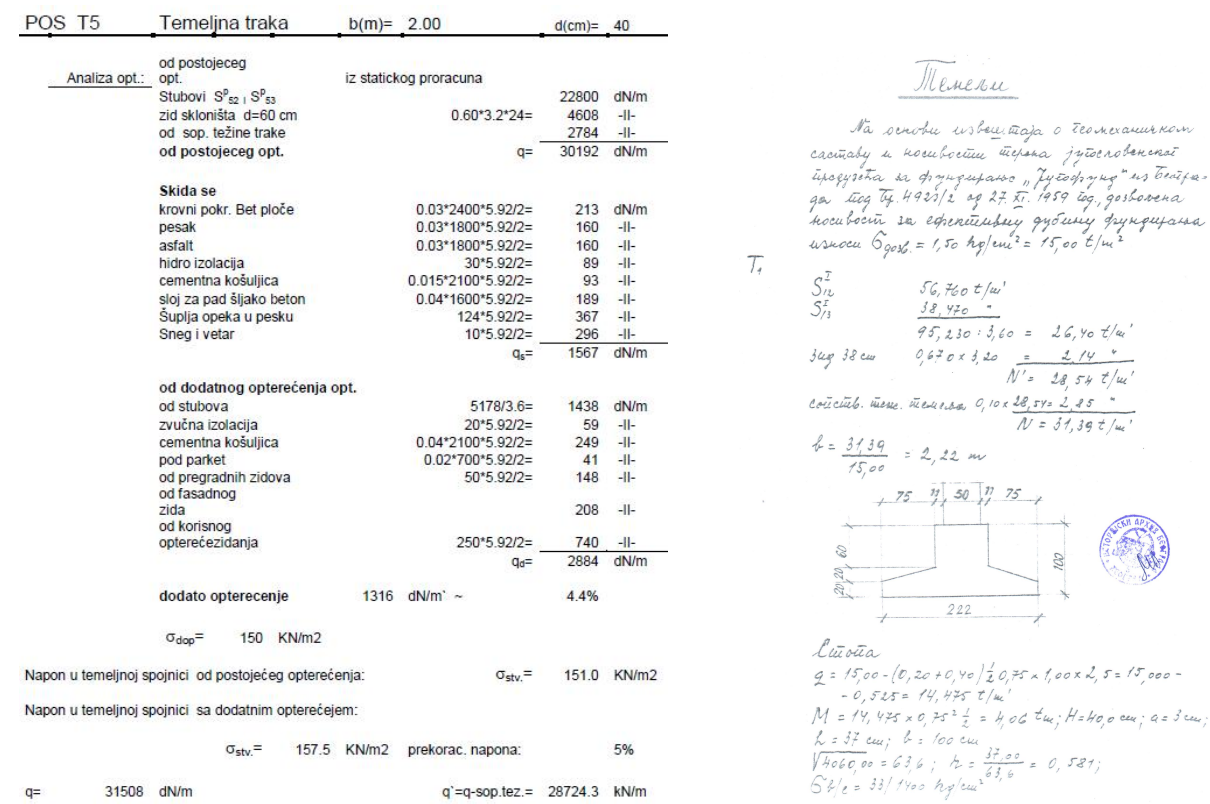

Slika 5 Kontrolni statički proračun postojećih temelja

\section{ZAKLJUČAK}

Kod dogradnji postojećih objekata mora se utvrditi da li postojeća konstrukcija može da primi novododate uticaje od dogradnje. Ukoliko to nije slučaj tada se postojeća konstrukcija mora ojačati, tj. sanirati. U vom slučaju dogradnje to nije bio slučaj. Pored navedenog potrebno je da se postojeća konstrukcija osigura i na seizmička dejstva, a u skladu sa Pravilnikom o izmenama i dopunama Pravilnika o tehničkim normativima za izgradnju objekata u seizmičkim područjima. Sprovedena analiza za kontrolni statički proračun je dokazala da je ukupno dodatno opterećenje cca $5 \%$, što je manje od dozvoljenog od $10 \%$, i kao takvo ne utiče bitno na promenu seizmičke otpornosti postojećeg objekta.

\section{LITERATURA:}

[1] Bešević, M.: Sanacija i rekonstrukcija nadzemnog dela objekta Univerzitetske biblioteke "Svetozar Markovic" u Beogradu, Simpozijum, SDGKJ, Dubrovnik 89: Simpozijum, SDGKJ, 1989, str. 71-75, UDK: knjiga T.

[2] Bešević, M.: Sanacija, adaptacija i rekonstrukcija porodicne zgrade u ulici Šefer u Parizu, Problem izgradnje i vrednovanja objekata- Građevinski fakultet ,Beograd, Aranđelovac 2000: Građevinski fakultet ,Beograd, 2000, str. 315- 324. 
[3] Bešević M., Vlajić.LJ," Sanacija adaptacija i dogradnja objekta u Nemanjinoj ulici br.9 u Beogradu", DGKS - 13. KONGRES, Zlatibor-Čigota, 2010 - ZBORNIK RADOVA, str. 445-452.

[4] Bešević M, T. Truić, Landović A, Kukaras D, "Analiza nosivosti spregnutih a.b. okruglih stubova sa krutim čeličnim profilima", Zbornik radova Građevinskog fakulteta Subotica, broj 19,(2010),str.79-92.

[5] Bešević M, "Savremeni pristup sanacija nosećih betonskih konstrukcija“ Zbornik građevinskog fakulteta Subotica, broj 21 (2012) YU ISSN 0352-6852.str.97-107.

[6] M. Bešević, A. Prokić," Diferent repair techniques for damaged reinforced concrete floor structure“, INDIS 2012, Planiranje, projektovanje, građenje i obnova graditeljstva, Dvanaesti međunarodni naučni skup, Novi Sad, 28-30 novembra 2012.

\title{
UPGRADING THE SIXTH FLOOR OF THE SCHOOL OF ELECTRICAL AND COMPUTER ENGINEERING OF APPLIED STUDIES IN VOJVODE STEPE STREET NO. 282 IN BELGRADE
}

\begin{abstract}
Summary: For the purpose of upgrading the sixth floor of The School of Electrical and Computer Engineering of Applied Studies in Belgrade, it was necessary to develop an upgrade design of the existing facility. The existing facility is located in Vojvode Stepe Street and it has $G f+5$ floors, with base (the part for upgrade) $36.8 \times 15.03 \mathrm{~m}$, and it is anticipated that facility will be upgraded with approx. $550 \mathrm{~m}^{2}$ in the form of mansard roof. Newly designed supporting structure for upgrade is in the form of a steel structure with a self-supporting sandwich Fe plasticized panels (most of the roof surface) in combination with wooden rafters on steeper roof flats, where intended roof covering is in the form of eternit panels. In static terms main supporting steel structure system is double-hinged frame supported by existing beam-columns in facade planes. Sheets, profiles and finished welded profiles (hip rafter) of steel quality S235 are used to create supporting steel structure, and extensions are achieved with ordinary screws of strength class 5.6 and corner welding seams. The existing building was constructed as a masonry structure with vertical reinforced concrete columns and vertical ring girder, while floor construction is designed as ribbed construction supported by the system of beams and vertical ring girders. Foundation of the structure was carried out on reinforced concrete two-way grid, with different cross-sections in accordance with the static actions.
\end{abstract}

Key words: upgrade, testing, recording, steel construction, extensions, reconstruction, recovery 